\title{
Risk-based stabilization planning for soil cut slopes
}

\author{
D. Li ${ }^{1}$, L. Zhang ${ }^{2}$, C. Zhou ${ }^{1}$, and W. Lu ${ }^{1}$ \\ ${ }^{1}$ State Key Laboratory of Water Resources and Hydropower Engineering Science, Wuhan University, 8 Donghu South Road, \\ Wuhan 430072, China \\ ${ }^{2}$ Department of Civil Engineering, Hong Kong University of Science and Technology, Clear Water Bay, Kowloon, Hong Kong
}

Received: 26 March 2009 - Revised: 20 July 2009 - Accepted: 3 August 2009 - Published: 6 August 2009

\begin{abstract}
Risk-based slope stabilization planning integrates the failure probability and the failure consequence systematically and shows promise for use in the practice. This paper attempts to develop a risk-based methodology for stabilization planning for deteriorating soil cut slopes. First, a framework of risk-based stabilization planning for slopes is proposed. Then the time-dependent reliability of deteriorating slopes is analyzed based on observed performance. Thereafter, the slope failure consequence is assessed in terms of expected numbers of fatality. After obtaining the timedependent risk of slope failure, the time for slope stabilization is determined according to selected risk criteria. Finally, the effect of slope maintenance on the reliability of slopes is evaluated. Based on the analyses, the annual probability of failure of soil cut slopes would increase exponentially in the early stage of service if no maintenance were implemented. As a slope deteriorates, the risk of slope failure increases with time and may reach an intolerable level at a certain time. The risk of slope failure may also reach an intolerable level due to a change of elements at risk. The derived stabilization time depends on the factors that cause the slopes to deteriorate, consequence of slope failure, selected risk criteria, and vulnerability of the affected population.
\end{abstract}

\section{Introduction}

Soil cut slopes are subject to deterioration and susceptible to failure, particularly during the rainy season or as a consequence of seismic events. In the context of the present study, slope deterioration refers to the effect of factors such as lack of maintenance of soil cut slope, blockage and dam-

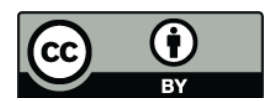

Correspondence to: $\mathrm{D} . \mathrm{Li}$

(dianqing@whu.edu.cn) age of surface drainage systems, surface or internal erosion, reduction of the shear strength of slope materials, and large changes in pore pressure (Lacerda and Santos, 2000; Cheung, 2004). Among these, inadequate slope maintenance or stabilization is a key factor (e.g. Lo et al., 1998; Chen and Lee, 2004).

A good practice for the maintenance of man-made slopes has been promulgated in Hong Kong by the Geotechnical Engineering Office (GEO) (GEO, 2003). Two major maintenance measures, namely, routine maintenance measures and preventive maintenance measures, are often taken (GEO, 2003). Routine maintenance, which entails only upkeep of the existing surface protective cover and drainage in a sound condition, would be effective in reducing the likelihood of failure of small-scale features or shallow failure of well-designed and constructed slopes. Approximately onefifth of the landslides might have been averted if adequate routine maintenance had been carried out (Wong and Ho, 1997). Preventive maintenance measures are deemed necessary when routine maintenance is not sufficient to prevent ongoing deterioration of the slopes. Preventive maintenance is intended to enhance protection to existing slopes and substantially reduce their rate of deterioration. Study by Wong and Ho (1997) indicated that about two-thirds of the landslides could have been averted if preventive maintenance had been carried out. The frequencies of routine maintenance and preventive maintenance can be found in Geoguide 5 (GEO, 2003). Chen and Lee (2004) concluded that routine maintenance is essential for slopes to avoid deterioration. Routine maintenance measures can effectively lower the permeability of the surface protection layer, minimize surface infiltration, and resist surface material erosion by running water. When the safety level of a slope is sufficiently low, stabilization actions such as preventive maintenance measures can be taken to bring the slope to a desired level of safety.

Published by Copernicus Publications on behalf of the European Geosciences Union. 
In the literature, Wyllie et al. (1980) studied slopestabilization planning using a decision-tree analysis. Roberds (1991) developed a methodology involving decision analysis for optimizing rock slope preventive maintenance programs. Lo et al. (1998) studied the effectiveness of maintenance in improving the slope safety. Shiu and Cheung (2003) assessed the global landslide risk posed by pre-1978 man-made slopes and the risk reduction from 1977 to 2000 achieved by landslip preventive measures in Hong Kong. Cheung (2004), and Cheung and Tang (2005a, b) developed a methodology to systematically evaluate the reliability of deteriorating slopes based on observed performance of soil-cut slopes in Hong Kong. Lee et al. (2006) developed a slope management system to manage the slope maintenance works for mountain highways in Taiwan. The Australian Geomechanics Society (AGS) (2007a) also promulgated geoguides for slope management and maintenance. However, time-dependent reliability of slopes and the effectiveness of slope maintenance in reducing the rate of deterioration have not been investigated sufficiently. How one can incorporate the time-dependent reliability into stabilization planning for deteriorating slopes and how to determine the time for slope stabilization have not been clearly specified. In addition, the risk posed by a particular slope usually change when the population and economic activities in the affected area expand. The risk level of the slope may therefore reach a limit that imposes slope stabilization actions. The construction of new towns in hilly terrains requires the risks be re-evaluated and the safety levels of these slopes enhanced. However, the change of elements at risk imposing stabilization actions has not been investigated sufficiently.

Risk-based stabilization planning is becoming a topic of great interest in engineering practice and has recently been used for offshore structures (Apeland and Aven, 2000), oil pipelines (Al-Khalil et al., 2005), landslides in Norwegian quick clay (Lacasse, 2004), and industrial sectors (Arunraj and Maiti, 2007). As risk is defined as the product of probability of slope failure and resulting adverse failure consequence; risk-based slope stabilization planning integrates the failure probability and the failure consequence systematically and helps in selecting alternatives to minimize the risk resulting from slope failure.

The objective of this paper is to develop a generic riskbased methodology for stabilization planning of deteriorating soil cut slopes. Several steps are taken towards the objective. Firstly, a framework of risk-based stabilization planning for slopes is proposed. Then the time-dependent reliability of slopes is analyzed based on observed performance of soil cut slopes. Thereafter, the slope failure consequence is assessed in terms of expected number of fatalities. After obtaining the time-dependent risk of slope failure, the time for slope stabilization is determined according to selected risk criteria. Finally, the effect of slope maintenance on the reliability of slopes is evaluated.

\section{Framework of risk-based stabilization planning for slopes}

Risk-based methodology provides a tool for slope stabilization planning and decision-making to reduce the probability of failure of slopes or the consequences of slope failure. The resulting maintenance or slope stabilization program maximizes the stability of the slope and minimizes the total maintenance cost. Risk-based slope stabilization comprises estimating the level of risk, deciding whether or not the risk level is acceptable, and implementing appropriate measures to reduce the risk when the risk level cannot be accepted. Figure 1 shows a flow diagram of the procedure used to develop this methodology. The procedure includes four components: identification of scope, risk assessment, risk evaluation, and stabilization planning based on risk. These components are described in the following sections.

\subsection{Identification of scope}

To ensure that the analysis addresses relevant issues and to limit the scope of analysis, it is important to define the following items:

1. The site, being the primary area of interest.

2. Will the analysis be limited to addressing property loss only, or will it also include injury to persons and loss of life?

3. The extent and nature of investigations that will be completed.

4. The basis for assessment of acceptable and tolerable risks.

\subsection{Risk assessment}

Risk assessment starts with the identification of major potential hazards that each failure scenario may lead to. Hazard is a description of the volume and probability of occurrence of the landslide. Hazard identification requires an understanding of the slope failure processes and the relationship between these processes and the geomorphology, geology, hydrogeology, climate, and vegetation at the site under concern. Then based on available data of slope failures in the past, the change of probability of slope failure with time and space could be estimated. The probability of slope failure includes the spatial probability and the temporal probability (Van Westen et al., 2006). The former is related to static environmental factors such as slope, strength parameters of materials, and depth. While the latter is related indirectly to some static environmental factors such as slope and hydraulic conductivity, and directly to dynamic factors such as rain input and drainage. Van Westen et al. (2006) discussed the difficulties related to the assessment of temporal and spatial probabilities. Determining the temporal and spatial probability is usually the most difficult part of the risk assessment 
and will require the majority of effort. It is, however, a key step in risk analysis. For the purpose of illustration, only the temporal probability of slope failure is considered in this study. The probability of slope failure is typically recommended to be expressed as the annual probability of slope failure. Thereafter, a consequence assessment is performed to quantify the impact of the slope failure. The consequences may not be limited to property damage and injury or loss of life. Other consequences such as public outrage, loss of business confidence, and damage to reputation may also be included. Many of these may not be readily quantifiable and will require considerable judgment if they are to be included in the assessment (Australian Geomechanics Society Landslide Taskforce, 2007b). Finally, the risk of slope failure can be quantified.

\subsection{Risk evaluation}

Risk acceptance criteria should be determined and used to decide whether the estimated risk of slope failure is acceptable or not. In this step, it is important to distinguish between acceptable risks that society desires to achieve, particularly for new projects, and tolerable risks that the public will live with, even though they would prefer lower risks. Acceptable risks are usually considered to be one order of magnitude lower than the tolerable risks (e.g., AGS, 2000). This applies to both loss of property and loss of life.

\subsection{Slope stabilization planning based on risk}

Slopes that fail to meet the risk acceptance criteria are investigated to develop a stabilization program to lower the risk within tolerable or acceptable limits. Both the type of stabilization measures and the maintenance time should be determined at this stage. In this study, we only use the determination of maintenance time as an example to illustrate the methodology. Both the probability of slope failure and the risk involved change with the maintenance time. The probability of failure after stabilization is finally calculated and the effect of maintenance on the reliability of slopes is evaluated.

\section{Time-dependent reliability of slopes}

Hong Kong is situated at the southern part of China. It has a total land area of about $1090 \mathrm{~km}^{2}$ and a population of about seven millions. Hong Kong has a tropical and subtropical climate. Thus the terrain is exposed to heavy precipitation particularly during the rainy season between April and September. On average, the annual rainfall is more than $2000 \mathrm{~mm}$, with a maximum reaching over $3000 \mathrm{~mm}$. The terrain of Hong Kong is covered by a thick mantle of decomposed rocks or colluvium (e.g. Fyfe et al., 2000). The granite is extensively weathered throughout the territory, with depths of silty, sandy soil of up to $60 \mathrm{~m}$. The volcanic rocks are

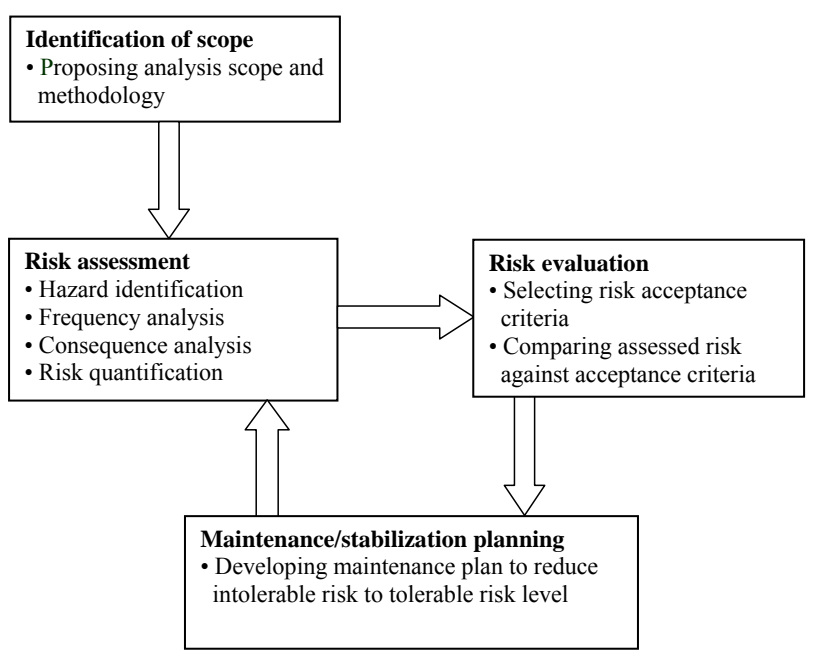

Fig. 1. Framework of risk-based stabilization for slopes.

more resistant to weathering than granite, and the soil mantle is up to about $20 \mathrm{~m}$ thick. The topography is generally steep, with more than $30 \%$ of the terrain steeper than $30^{\circ}$. Due to the lack of flat areas, developments are usually concentrated on steep topography. As a result, more than 55000 registered slope features (i.e. cuts, fills and retaining walls) have been formed throughout the territory. A registered slope feature is a man-made feature that satisfies a set of criteria. For instance, if a slope height is greater than $3 \mathrm{~m}$ it is eligible for registration. Among the slopes, some 35000 were formed prior to 1978 when the Hong Kong government commenced the regulatory control on geotechnical works. These old slopes are commonly referred to as "pre-1978 slopes". They were designed and constructed primarily on the basis of judgment and rules of thumb (Brand, 1985). Cut slope angles are commonly $40-70^{\circ}$ and most of the slopes are too steep by the current design standard. These slopes were commonly formed in association with land formation for housing development and road works in the steep mantle of decomposed rocks. Figure 2 shows the locations of these pre-1978 manmade slopes in the territory of Hong Kong. The remaining 20000 slopes, which are referred to as "post-1978 slopes", were designed and constructed in accordance with a wellestablished safety standard. The standard includes site characterization by field and laboratory tests, stability analysis and design, and supervision of construction works. Note that among the pre-1978 slopes, 21000 out of 35000 are soil cut slopes, and this slope type contributes to more than $80 \%$ of the global landslide risk in the territory of Hong Kong (Cheung et al., 2001). Therefore, soil cut slopes in Hong Kong are adopted for the current study. 


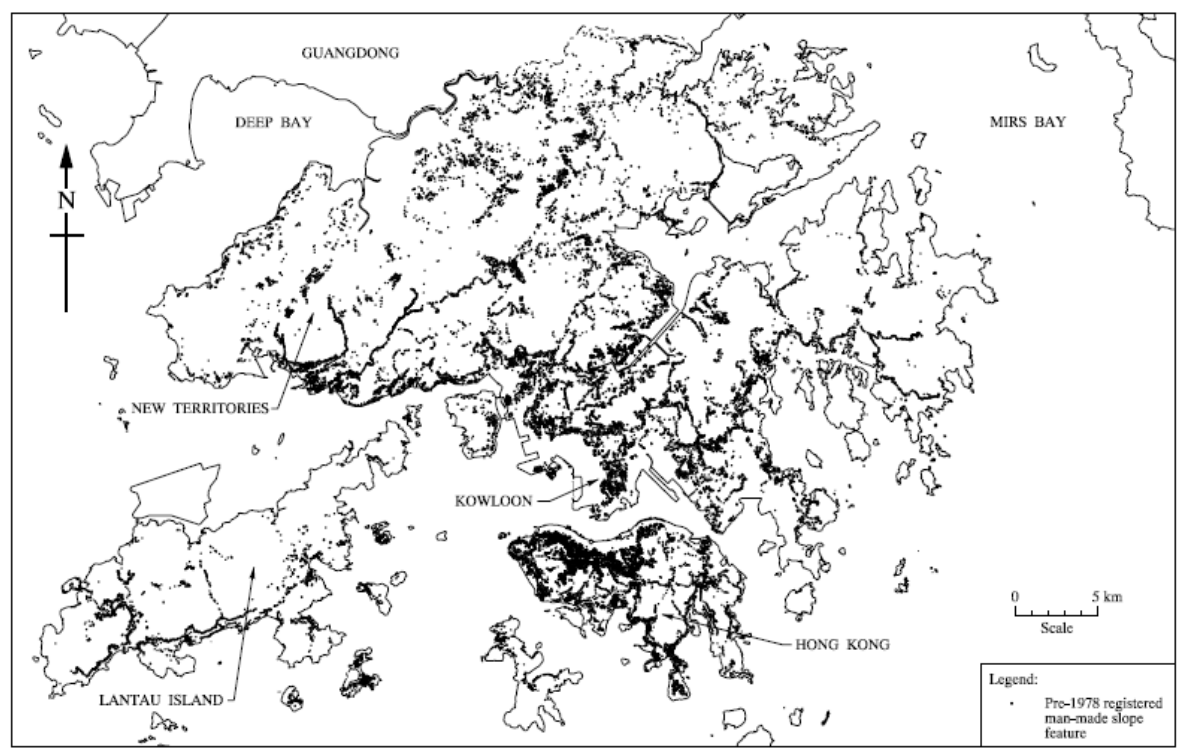

Fig. 2. Locations of pre-1978 registered man-made slopes in the territory of Hong Kong.

Hundreds of rainfall-induced landslides are reported each year in Hong Kong. Most of the slip surfaces are shallow, and the thickness of scars is usually less than $3 \mathrm{~m}$. If a landslide occurs, more than $80 \%$ of the debris volume is less than $50 \mathrm{~m}^{3}$ (Cheung et al., 2001). To reduce the landslide risk to as low a level as is reasonably practicable, a comprehensive slope safety system has been established to manage landslide risk in Hong Kong. As part of the system, a territory-wide automatic rain-gauge network has been established to study the spatial characteristics of rainfall as well as its correlation with landslides. Rainfall data are recorded automatically at 5-minute intervals on a 24-h basis. In the context of this paper, a rainstorm is defined as an event in which a rolling 24-h rainfall, $i_{24}$, exceeds $50 \mathrm{~mm}$. For each rainstorm event, the maximum rolling 24-h rainfall values were calculated for each raingauge. Studies (Premchitt et al., 1994; Yu, 2004) indicated that the maximum rolling $24-\mathrm{h}$ rainfall, $i_{24}$ max , correlates reasonably well with the occurrence of landslides and $i_{24 \text { max }}$ is a good parameter to indicate the likelihood of landslides. For instance, Yu (2004) reported a correlation study between rainfall and landslide frequency based on 1622 slope failures occurred in the years 1984 to 2000 and studied influence factors such as slope height and angle. For the population of soil cut slopes considered, the landslide frequency (in $\log$ scale) increases approximately linearly with $i_{24}$ max between $50 \mathrm{~mm}$ to $350 \mathrm{~mm}$. The correlation coefficient is about 0.9 on average.

In a previous research program by Cheung (2004), Siu and Cheung (2003), Tang and Cheung (2004), and Cheung and Tang (2005b), approximately 16000 soil cut slopes from a population of 21000 soil cut slopes with observed performance records during 208 rainstorms in the period from 1984 to 2002 were selected for study. Most of these slopes were formed before the implementation of more rigorous geotechnical control in 1977. Based on the past performance data of soil cut slopes (i.e., time of formation and time of first failure of the pre-1978 soil cut slopes in the period of 1984 to 2002), a statistical reliability analysis has been carried out. The youngest and oldest pre-1978 slopes were 7 and 31 years old respectively in 1984 . By the end of 2002, these slopes were 26 and 50 years old, respectively. More than 1100 landslide accidents were reported over the observation period. To study the reliability of slopes under different rainfall characteristics, the territory of Hong Kong were divided into a grid of 1600 small cells, and 860 cells among them fall on land as shown in Fig. 3. Each cell has a plan area of $1.5 \mathrm{~km} \times 1.2 \mathrm{~km}$. Based on the locations of soil cut slopes, the number of slopes in each of the 1600 cells can be determined. The spatial distribution of 16000 soil cut slopes in the territory of Hong Kong is also shown in Fig. 3, where the numbers represent the numbers of slopes in the subject cells. Whenever a rainstorm occurs, the rainfall data recorded by rain gauges will be used to interpolate the rainfall intensity at each of the 1600 cells (Yu, 2004). For each of the 208 rainstorms, the geographical characteristics of the rainfall are represented by the spatial distribution of the maximum rolling 24-h rainfall among the 1600 cells. Each cell has its own $i_{24} \max$.

The rainfall intensity, $i_{24} \max$, was divided into three categories: $\quad 50-200 \mathrm{~mm} /$ day, $\quad 200-400 \mathrm{~mm} /$ day, and $>400 \mathrm{~mm} /$ day. These categories were adopted because the performance of the old soil cut slopes under these categories of rainfall intensity was quite different (Cheung and Tang, 2005b). For example, Premchitt (1991) noted that landslides are almost certain to occur in Hong Kong whenever $i_{24} \max$ exceeds $200 \mathrm{~mm} /$ day. Further study on the 


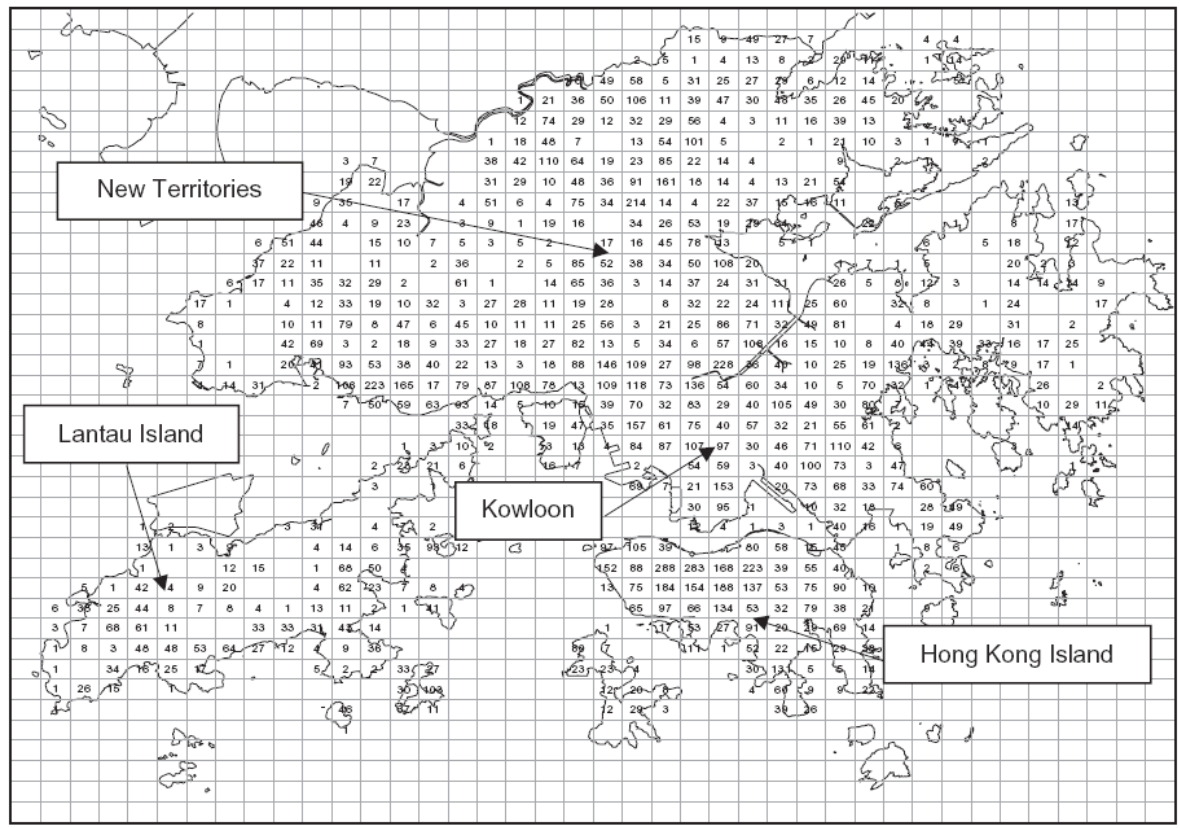

Fig. 3. Spatial distribution of soil cut slopes in the territory of Hong Kong (after Cheung and Tang, 2005b).

relationship between the probability of landslide occurrence and rainfall intensity can be found in the literature, such as Finlay et al. (1997), Au (1998), Yu (2004), and Chen et al. (2005). If the time of occurrence of a landslide is within the start of a rainstorm and further two days after the end of the rainstorm, the landslide would be considered as triggered by this rainstorm. For each of the rainstorms, the soil cut slopes and resulting landslides in response to the three rainfall intensity categories from each of the small cells were also identified and grouped. The number of slopes hit by rainstorms, namely, the number of slopes multiplied by the number of rainstorms, was then grouped according to slope age and rainfall intensity. The grouping of rainstorm hits for the 208 rainstorms under different categories of rainfall intensity and slope ages is shown in Fig. 4. Similar grouping was carried out for slope failures, as shown in Fig. 5, which records the first time that a slope failed. Once a slope has failed, it will be excluded from the sample of slopes in the next rainstorm event. In this paper, these valuable data are used as a basis for analyzing time-dependent reliability of the soil cut slopes. Note that the number of rainstorm hits with $i_{24} \max =50-200 \mathrm{~mm} / \mathrm{day}$ is 3057589 which is the highest among the three rainstorm categories, yet the number of resulting landslides is 333 that is not the largest. In contrast, although the number of rainstorm hits with $i_{24} \max >400 \mathrm{~mm} /$ day is 16438 that is the smallest, these heavy rainstorms induced 147 landslides.

In the following analysis, the slope population is assumed to be homogeneous and the temporal and spatial distributions of heavy rainstorms relative to the locations of slopes of dif- ferent vulnerabilities are not taken into account. Therefore, the resulting time-dependent reliability of slopes is "global" rather than site specific; site-specific study would be required to develop a slope stabilization plan for a particular site or region.

Based on the datasets in Figs. 4 and 5, the conditional annual probability of failure as a function of age $t$ can be estimated as (Cheung and Tang, 2005b):

$\widehat{h}\left(t, i_{24 \max }\right)=$

Number of $t$-year-old slopes that failed at a rainstorm of intensity $i_{24}$ max

Number of rainstorm hits of intensity $i_{24} \max$ on $t$-year-old slopes

The conditional rate of failure given by Eq. (1) is equivalent to the hazard function that is commonly used in reliability analysis to denote the instantaneous rate of failure for an operating system. The Weibull distribution is a popular model for describing the relative likelihood of failure for a deteriorating engineering system (Harr, 1997). For example, Cheung and Tang (2005b) applied the Weibull distribution to deteriorating slopes. The hazard function $h(t)$ for a Weibulldistributed time to failure $t$ is expressed as

$h(t)=\lambda \gamma(\lambda t)^{\gamma-1}$

where $\gamma=\mathrm{a}$ shape parameter that governs the rate of change of the hazard function; and $\lambda=$ a scale parameter which dictates the spread of the distribution. The cumulative hazard function can be obtained as

$H(t)=\int_{0}^{t} h(t) d t=(\lambda t)^{\gamma}$ 


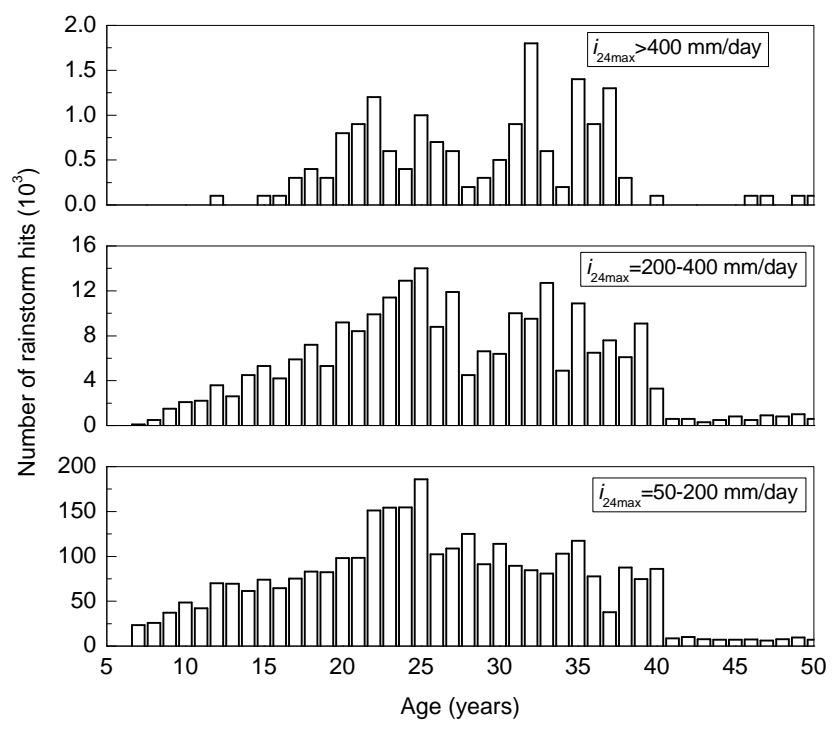

Fig. 4. Number of rainstorm hits on pre-1978 soil cut slopes by age of slope (After Cheung and Tang, 2005b).

Based on Eqs. (2) and (3), hazard functions of the slope performance data with respect to the three categories of rainfall intensity can be constructed following methods proposed by Nelson (1972) and Cheung (2004). Figure 6 shows the hazard plot corresponding to $i_{24} \max >400 \mathrm{~mm} /$ day in log-log scale. The corresponding correlation coefficient is 0.991, which indicates that the observed time to failure fits a Weibull distribution well. The shape parameter, $\gamma$, and the scale parameter, $\lambda$, of the Weibull distribution are determined from the gradient and intercept of the regression line, respectively. They are estimated to be $\widehat{\gamma}=1.94$ and $\widehat{\lambda}=0.012$. The values of parameters $\gamma$ and $\lambda$ for the hazard function associated with the three categories of rainfall intensity before and after rigorous maintenance are summarized in Table 1. Note that the hazard analysis involves two sources of uncertainty: parameter uncertainty affected by the number of data available and model uncertainty associated with the selected twoparameter Weibull distribution.

Figure 7 shows the three hazard functions on log scale under different railfall intensities. Since all $\gamma$ values shown in Table 1 are greater than unity, all the hazard functions increase monotonically with slope ages. In Fig. 7, the performance of the slopes under rainstorm categories $i_{24 \max }=50-200$ and $200-400 \mathrm{~mm} /$ day exhibits discontinuities at $t=16$ years on the curves. One possible reason for this lower rate could be retardation of deterioration. After a reasonably long period of service, for the considered case of 16 years, owners of the slopes might have become aware of the poor conditions of their slopes and carried out maintenance works that counterbalanced the effect of deterioration. Indeed, as reported by Cheung and Tang (2005b), a public campaign on slope maintenance was initiated in 1992 to in-

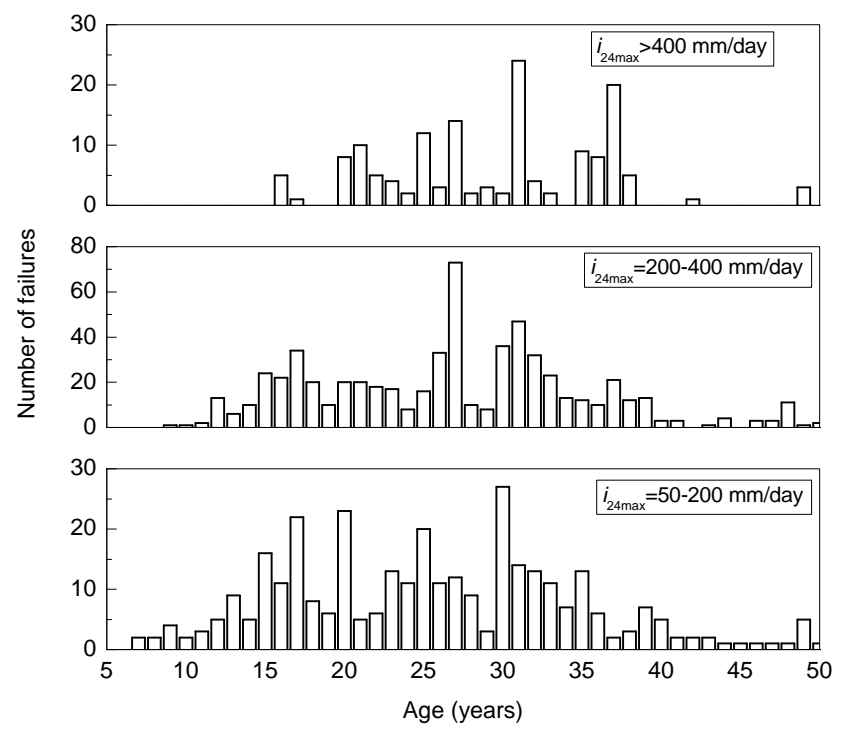

Fig. 5. Number of pre-1978 soil cut slope failures by age of slope (After Cheung and Tang, 2005b).

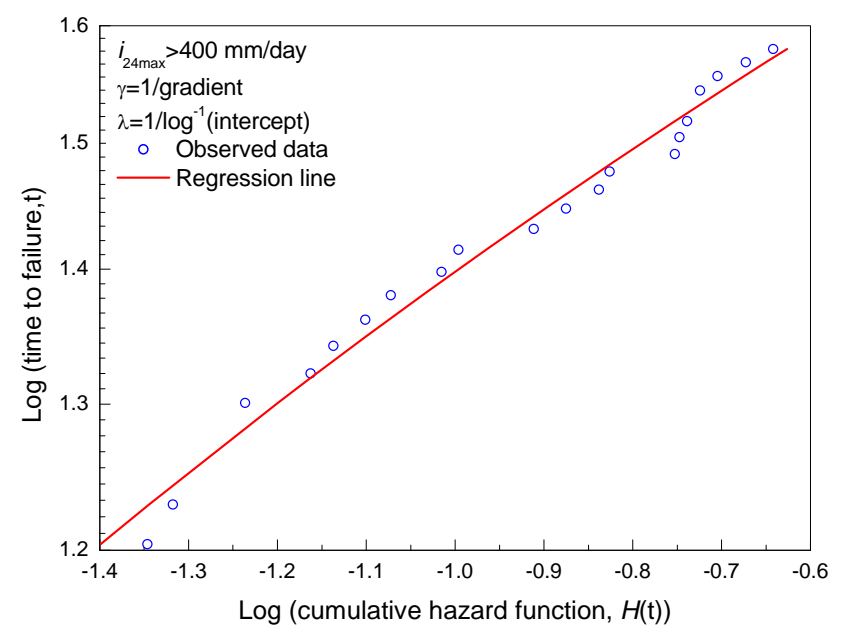

Fig. 6. Hazard plotting for time of slope failure using Eq. (2).

crease public awareness of the importance of slope maintenance and the owners' liability to keep their slopes in good condition. The youngest slopes in the population were 16 years old in 1992, understanding that a certain level of maintenance work was also conducted before 1976. Maintenance of these slopes generally on an annual basis has been carried out in a more planned manner since then and the rate of slope failure after $t=16$ years has therefore been reduced. Another possible reason for a lower rate of increase in failure probability is that the slopes that have been load-prooftested for 16 years may perform better than those that have already failed. Strictly speaking, the hazard functions shown in Fig. 7 represent only the average reliability of soil cut slopes. Although the slopes are from a similar class, they 
Table 1. Weibull distribution parameters in Eq. (2) for deteriorating slopes.

\begin{tabular}{lrrrrrr}
\hline & \multicolumn{3}{c}{ Before maintenance } & \multicolumn{3}{c}{ After maintenance } \\
\cline { 2 - 8 } $\begin{array}{l}\text { Rainfall intensity, } \\
i_{24 \text { max }}(\mathrm{mm} / \text { day) }\end{array}$ & $\gamma$ & $\lambda$ & $\begin{array}{r}\text { Correlation } \\
\text { coefficient }\end{array}$ & $\gamma$ & $\lambda$ & $\begin{array}{r}\text { Correlation } \\
\text { coefficient }\end{array}$ \\
\hline $50-200$ & 2.84 & 0.0056 & 0.988 & 1.28 & 0.0003 & 0.994 \\
$200-400$ & 6.54 & 0.036 & 0.989 & 1.48 & 0.0048 & 0.995 \\
$>400$ & 1.94 & 0.012 & 0.991 & 1.94 & 0.012 & 0.991 \\
\hline
\end{tabular}

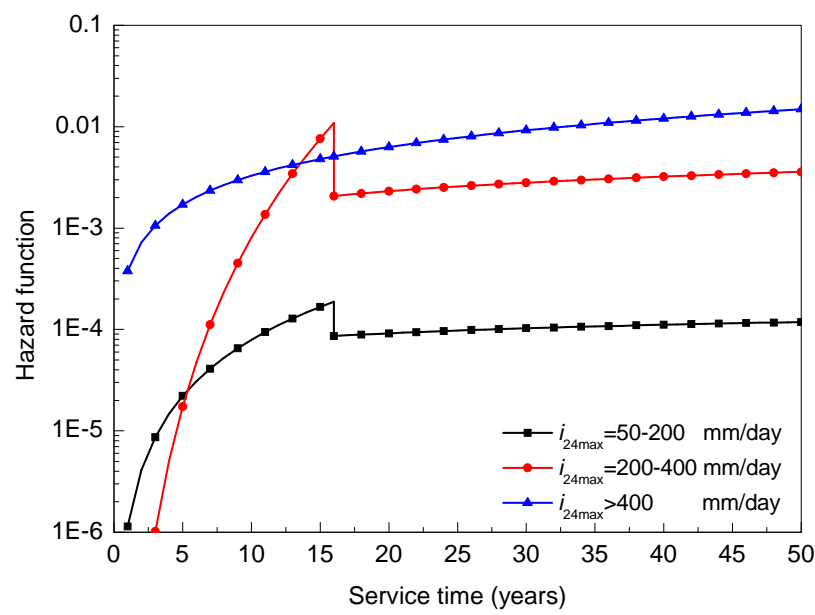

Fig. 7. Variation of hazard function over time using Eq. (2) under different categories of rainfall intensity (After Cheung and Tang, 2005b).

have different characteristics such as geometrical configurations and applied loads. Thus the strength characteristics of the slopes that survived after 16 years may be different from those that have already failed. The weaker slopes may have already failed in the early service period.

In addition to the hazard function, a designer may be interested in knowing the probability of failure over a given future service time. One can integrate the probability density function of the time to failure and obtain the probability of slope failure for a service period $t[0, T]$ as follows:

$P_{f}(t)=1-\exp (-\lambda t)^{\gamma}$

Applying Eq. (4), the cumulative probabilities of slope failure for the three categories of rainfall intensity are obtained and shown in log scale in Fig. 8. The cumulative probability of failure increases as the service time or the rainfall intensity increases. For example, a slope would have a $P_{f}$ of $0.2 \%$ under $i_{24} \max =50-200 \mathrm{~mm} /$ day for the next 25 years. The $P_{f}$ will become $0.5 \%$ if the service period increases from 25 years to 50 years. On the other hand, if $i_{24}$ max increases to $200-400 \mathrm{~mm} /$ day and $>400 \mathrm{~mm} /$ day, the $P_{f}$ for the next 25 years will increase to $4 \%$ and $10 \%$, respectively. Note that the kinks in the probability curves when the service time

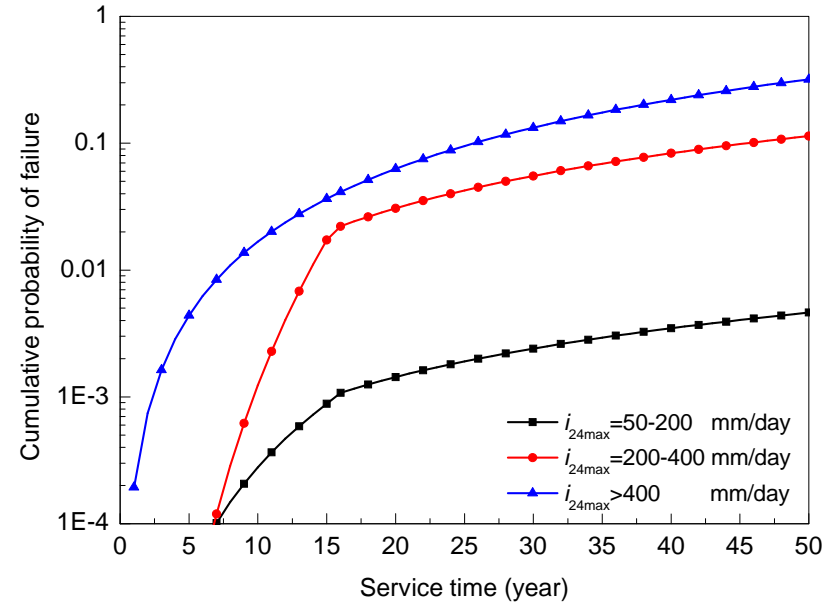

Fig. 8. Cumulative probability of failure using Eq. (4) under different categories of rainfall intensity.

reaches 16 years represent the change in the Weibull distribution parameters at $t=16$ years. The rate of increase in the probability of failure beyond 16 years is lower, which will be discussed later.

The probabilities of failure shown in Fig. 8 only represent the contribution of each different category of rainstorm to the conditional probability of failure. If the occurrence probabilities of different rainstorm intensities are taken into account, one can determine the probabilities of slope failure for various service periods by virtue of the total probability theorem (e.g., Ang and Tang, 2007),

$P_{f t}(t)=\sum_{i=1}^{3} P_{f i}(t) P_{i}\left(i_{24 \max }\right)$

where $P_{i}\left(i_{24} \max \right)=$ occurrence probability of the $i$ th category of rainstorm intensity; and $P_{f i}(t)=$ cumulative probability of slope failure for a service period $t$ shown in Eq. (4). Lam and Leung (1994) established the occurrence probability of different rainstorm intensities based on past rainfall records. The occurrence probabilities of rainstorm are calculated based on the past hourly and daily rainfall data for the periods spanning from 1884 to 1939 and from 1947 to 1990. The occurrence probabilities of rainstorm categories 
$i_{24 \max }=50-200,200-400$, and $>400 \mathrm{~mm} /$ day in a given year are found to be 43,50 , and $7 \%$, respectively. It should be noted that the occurrence probability of rainstorm highly depends on the rainfall duration. For example, the occurrence probabilities of the maximum rolling 12-h rainfall categories $i_{12 \max }=50-200,200-400$, and $>400 \mathrm{~mm} /$ day in a given year are 65,33 , and $2 \%$, respectively. Similarly, the occurrence probabilities of the maximum rolling 6-h rainfall are 82.5, 17, and $0.5 \%$, respectively. Generally, the occurrence probability of rainstorm category $50-200 \mathrm{~mm} /$ day decreases with increasing rainfall duration, while the occurrence probabilities of rainstorm categories $i_{12 \max }=200-400$ and $>400 \mathrm{~mm} /$ day increase with increasing rainfall duration. Again these rainfall occurrence data are "global estimates" and may not be applicable to a specific site. Based on these data, the cumulative probability of slope failure over any given service period can be determined and are shown in Fig. 9. The cumulative probability of failure increases with service time and results independent of the rainfall category. For instance, it increases from $0.03 \%$ for a service time of 5 years to $8 \%$ for a service time of 50 years. As indicated earlier, the kink observed at a service time of 16 years is due to the change in the deterioration rate of slopes because of different levels of maintenance.

The annual probability of failure is of interest to planners in assessing the risk arising from slope failures. Based on Eq. (5), the annual probability of slope failure in year $t$ can be calculated by

$$
\begin{aligned}
P_{f a}(t) & =P_{f t}(t)-P_{f t}(t-1) \\
& =\sum_{i=1}^{3}\left(P_{f i}(t)-P_{f i}(t-1)\right) P_{i}\left(i_{24 \max }\right)
\end{aligned}
$$

Figure 10 shows the annual probability of failure in any year $t$ within the given service period. It is evident that the rate of slope deterioration increases significantly when the service time is longer than a decade. For example, the annual failure probability increases from $0.01 \%$ at a service time of 5 years to $0.4 \%$ at a service time of 15 years. This means that the time of slope maintenance should be smaller than a decade in order to alleviate the rate of slope deterioration efficiently. After the majority of maintenance or stabilization works were initiated in the 16th year, the annual probability of failure after $t=16$ years is reduced substantially and increases with time more slowly. The change of failure rate with time can be modelled as a bathtub curve (e.g. Harr, 1997): the deteriorating rate of slopes with proper maintenance slows down with time. The surviving slopes after age 16 may have geometrical and strength characteristics different from those that have already failed. The weaker slopes may have already failed in the early service period.

Maintenance works alone might not be able to bring the annual probability of slope failure back to the original level when the slope was just formed. There are a few reasons for this. First, although all government slopes in Hong Kong

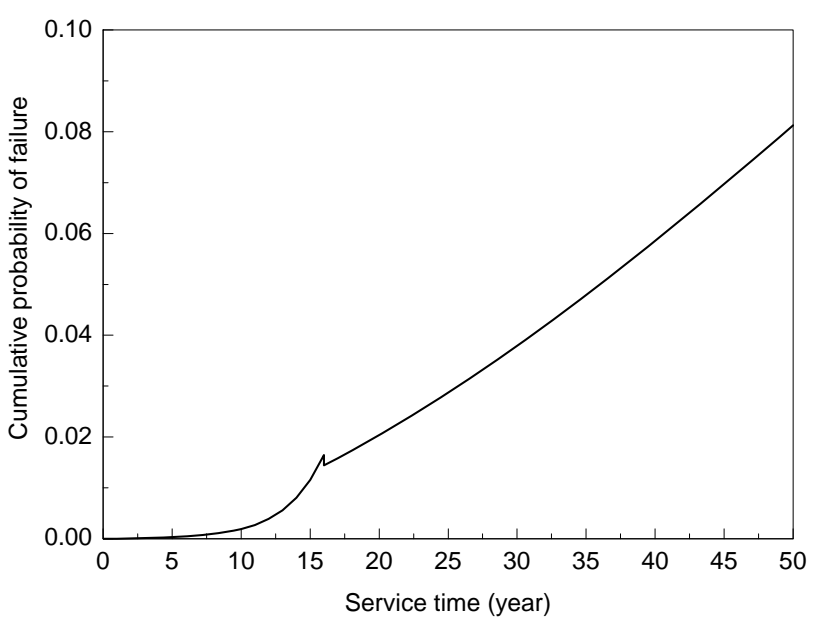

Fig. 9. Cumulative probability of slope failure using Eq. (5) for various service periods.

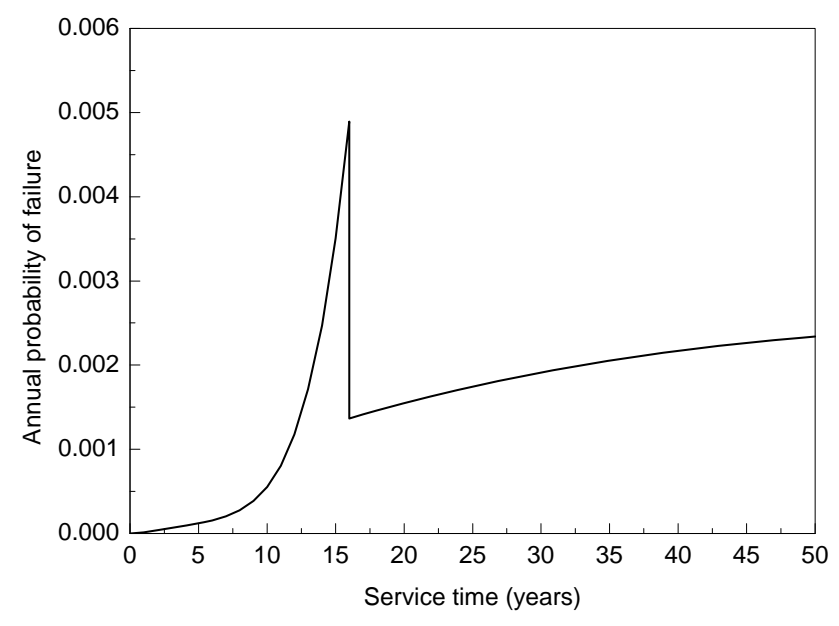

Fig. 10. Annual probability of slope failure using Eq. (6) for various service periods.

are subject to routine maintenance carried out generally on annual basis since 1992, preventive maintenance measures were not implemented on all the deteriorated slopes. Second, some factors such as reduction of soil shear strength due to weathering of slope forming materials or seasonal variations of pore pressure are irreversible.

Besides predicting the performance of old slopes when they were first constructed, it is desirable that the risk in the remaining life of those slopes that have not failed can be obtained. For instance, one would be interested in estimating the reliability of existing slopes of any given age over any given next service period so that planners can schedule the maintenance program for these deteriorating slopes. The failure probability of slopes older than $t_{0}$ for the next period $t_{1}$ has been given by Cheung and Tang (2005a),

$P_{f}\left(T<t_{0}+t_{1} \mid T \geq t_{0}\right)=1-\exp \left(-\lambda^{\gamma}\left(\left(t_{0}+t_{1}\right)^{\gamma}-t_{0}^{\gamma}\right)\right)$ 
Equation (7) provides a model for estimating the reliability of slopes of a given age in future service period. Based on Eq. (7), the annual failure probability of slopes of age $t_{0}$ in year $t_{1}$ in the new service period can be determined as follows:

$$
\begin{aligned}
& P_{f a}\left(T<t_{0}+t_{1} \mid T \geq t_{0}\right)=\exp \left(-\lambda^{\gamma}\left(\left(t_{0}+t_{1}-1\right)^{\gamma}-t_{0}^{\gamma}\right)\right)(8) \\
& \quad-\exp \left(-\lambda^{\gamma}\left(\left(t_{0}+t_{1}\right)^{\gamma}-t_{0}^{\gamma}\right)\right)
\end{aligned}
$$

The annual probabilities of failure for slopes of various ages are calculated using Eq. (8) and shown in Fig. 11. After serving for many years with normal maintenance, the annual failure probability does not increase with service time significantly. As expected, the annual failure probabilities for older slopes are higher than those for younger slopes given the same service period. For example, annual probabilities of failure of the 10-, 20- and 30-year old slopes are projected to be $0.16,0.20$ and $0.24 \%$ over the next 10 -year service. The annual probabilities of failure of slopes of different ages become similar as the service time increases.

Having obtained the annual probability of slope failure, an example is investigated to validate the proposed methodology. In Hong Kong, there were a total of six rainstorms in 2003 and the spatial distribution of the maximum rolling 24$\mathrm{h}$ intensity $i_{24}$ max of each rainstorm among the cells has been determined. Based on the spatial distribution of the rainfall intensity, one can use Eq. (6) to calculate the annual probability of failure. Then, the number of soil cut slope failures induced by each rainstorm can be predicted. Table 2 compares the predicted number with the actual number of soil cut slope failures (Cheung and Tang, 2005b). Fairly good agreement between the predicted and the actual number of soil cut slope failures is observed. More data should be collected to predict the number of soil cut slope failures in a more reliable way.

\section{Consequence of slope failure}

In the previous section, the annual probability of slope failure has been determined based on observed global performance of soil cut slopes in Hong Kong. In order to assess the risk of slope failure, the consequence of slope failure and vulnerability of elements at risk must also be available. The consequences of slope failure include loss of property, loss of life, public outrage, political effects, damage to reputation, and others (AGS, 2000). For illustrative purposes, only the number of deaths by soil cut slope failure considered here. Wong et al. (1997) developed a methodology in which the consequence of a given slope failure is expressed in terms of Potential Loss of Life (PLL). Table 3 shows the expected number of fatalities for different facilities directly affected by a reference landslide that is $10 \mathrm{~m}$ in width and $50 \mathrm{~m}^{3}$ in volume. The expected number of fatalities for facility groups 1 and 2 are in the same order of magnitude, which are one or two or-

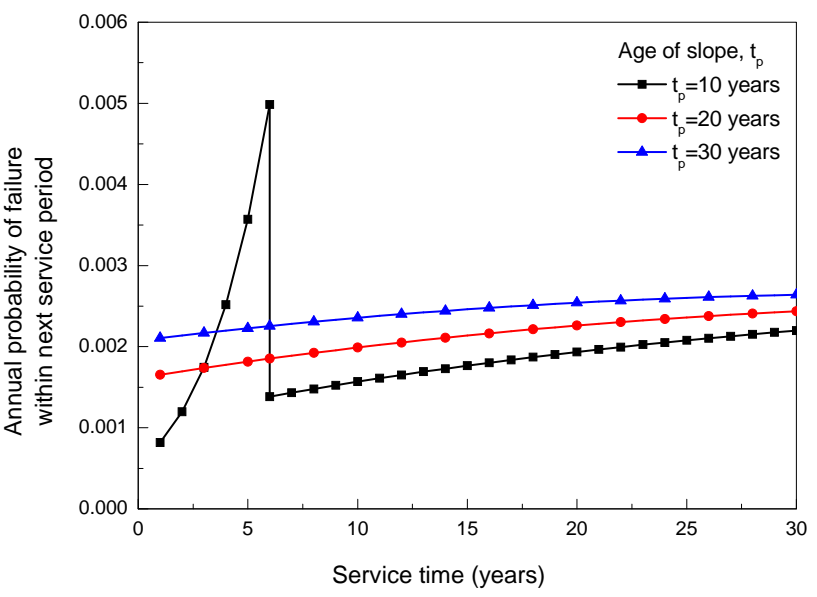

Fig. 11. Annual probability of failure using Eq. (8) for soil cut slopes with different ages.

Table 2. Comparison between predicted and actual number of soil cut slope failures in 2003 in Hong Kong (after Cheung and Tang, 2005b).

\begin{tabular}{llcc}
\hline Rainstorm & Period & $\begin{array}{c}\text { Actual number } \\
\text { of soil cut } \\
\text { slope failures }\end{array}$ & $\begin{array}{c}\text { Predicted number } \\
\text { of soil cut } \\
\text { slope failures }\end{array}$ \\
\hline 1 & 7-10 April & 1 & 2 \\
2 & 4-7 May & 38 & 43 \\
3 & 9-16 June & 18 & 23 \\
4 & 21-26 August & 4 & 3 \\
5 & 1-4 September & 3 & 2 \\
6 & 14-17 September & 2 & 5 \\
\hline
\end{tabular}

ders of magnitude larger than those for facility groups 3,4 , and 5 .

Vulnerability is the degree of loss to a given element or set of elements within the area affected by the landslides (Varnes, 1984; Fell, 1994; Glade, 2003). It can always be measured in the range from 0 (no damage) to 1 (total loss). For loss of life, vulnerability is the probability that a particular life will be lost given that the landslide occurs. Vulnerability assessment involves the understanding of the interaction between a given landslide and the affected elements. Generally, it should consider factors such as landslide volume, depth of landslide, travel distance, travel speed, and elements at risk. Finlay et al. (1999) provided some data on vulnerability of a person hit in open space, in a vehicle, or in a building by a landslide in Hong Kong. A person was found to be very vulnerable in the event of complete or substantial burial by debris, or the collapse of a building. Although this investigation is based on research in Hong Kong, it gives a first introduction to the different kinds of vulnerability that can apply to people. 
Table 3. Expected number of fatalities for affected facilities used in the analysis (After Wong et al., 1997).

\begin{tabular}{|c|c|c|}
\hline $\begin{array}{l}\text { Facility } \\
\text { Group No. }\end{array}$ & Facilities & $\begin{array}{l}\text { Expected No. } \\
\text { of fatalities }\end{array}$ \\
\hline 1 & $\begin{array}{l}\text { (a) Heavily used buildings } \\
\text { Residential building, commercial office, store and shop, hotel, factory, school, power station, } \\
\text { ambulance depot, market, hospital, polyclinic, clinic, welfare centre } \\
\text { (b) Others } \\
\text { Cottage, licensed and squatter area } \\
\text { Bus shelter, railway platform and other sheltered public waiting area } \\
\text { Dangerous goods storage site (e.g., petrol stations) } \\
\text { Road with very heavy vehicular or pedestrian traffic density }\end{array}$ & 3 \\
\hline 2 & $\begin{array}{l}\text { (a) Lightly used buildings } \\
\text { Indoor car park, building within barracks, abattoir incinerator, indoor games' sport hall, sewage } \\
\text { treatment plant, refuse transfer station, church, temple, monastery, civic centre, manned sub- } \\
\text { station } \\
\text { (b) Others } \\
\text { Major infrastructure facility (e.g., railway, tramway, flyover, subway, tunnel portal, service } \\
\text { reservoir) } \\
\text { Construction site (if future use not certain) } \\
\text { Road with heavy vehicular or pedestrian traffic density }\end{array}$ & 1 \\
\hline 3 & $\begin{array}{l}\text { Heavily used open space and public waiting area (e.g., heavily used playground, open car park, } \\
\text { heavily used sitting out area, horticulture garden) } \\
\text { Road with moderate vehicular or pedestrian traffic density }\end{array}$ & 0.25 \\
\hline 4 & $\begin{array}{l}\text { Lightly used open-air recreation area (e.g., district open space, lightly used playground, ceme- } \\
\text { tery, columbarium) } \\
\text { Non-dangerous goods storage site } \\
\text { Road with low vehicular or pedestrian traffic density }\end{array}$ & 0.03 \\
\hline 5 & $\begin{array}{l}\text { Remote area (e.g., country park, undeveloped green belt, abandoned quarry) } \\
\text { Road with very low vehicular or pedestrian traffic density }\end{array}$ & 0.001 \\
\hline
\end{tabular}

Note: (i) The expected number of fatalities refers to the occurrence of a reference landslide, namely, a $10 \mathrm{~m}$-wide failure $50 \mathrm{~m}^{3}$ in volume. (ii) To account for the different types of building structures with different detailing of window and other perforations etc, a multiple fatality factor ranging from 1 to 5 is considered appropriate for group No. 1(a) facilities to account for the possibility that some incidents may result in a disproportionately larger number of fatalities than that envisaged. For global QRA, an average value of 3 is taken for the multiple fatality factors.

(iii) For incidents that involve the collapse of a building, it is assumed that the expected number of fatalities is 100.

\section{Risk assessment and acceptance criteria of slope failure}

Having determined the probability of slope failure, the consequence of slope failure, and the vulnerability factor, the risk of slope failure can be obtained. Aiming at assessing the risk of slope failure, the scale of slope failure was assumed to be the same as the reference landslide, namely, a slide $10 \mathrm{~m}$ in width and $50 \mathrm{~m}^{3}$ in volume. It should be noted, however, that if the actual slide size were different from the reference one, then the expected number of fatalities should be scaled proportional to the ratio of the actual size to the reference size. Two types of risk, namely, individual risk and societal risk are considered, which are presented in terms of specific risk (SR) and total risk (TR) (Varnes, 1984), respectively. Following Varnes (1984), the specific risk is defined as probability times vulnerability for a given element, and the total risk is the sum of specific risks over all potential landslides in the study area. Thus, the specific risk for a slope failure can be calculated as the summation of the product of the probability of slope failure and the vulnerability of the most vulnerable individual occupying the facility for each of the landslide scenarios. The total risk can be calculated by summing up the product of the probability of slope failure affecting the facility, the vulnerability of the affected population, and the average population at the facility, for each of the landslide scenarios (Muir et al., 2006). For illustrative purpose, only one failure mode and one corresponding 
consequence associated with slope failure are considered in this study. As a slope deteriorates, the risk increases with time and may reach an unacceptable limit at a certain time. The risk of slope failure may also reach an unacceptable limit due to a change of elements at risk. The time for maintenance can be determined when the risk-time relation is found and appropriate risk acceptance criteria are selected.

As pointed out by Morgenstern (1997), appropriate risk acceptance criteria are crucial to extend the use of landslide risk assessment in practice. Following a review of acceptable risks and psychology of risk perception, Finlay and Fell (1997) studied the landslide risk perception in Australia and Hong Kong. They suggested that the acceptable SR ranges from $10^{-3}$ to $10^{-6}$ per year. Based on a survey of literature concerning acceptable risk for dams, Fell and Hartford (1997) proposed tolerable risk levels for loss of life in relation to slope failures. For existing slopes only including artificial or man-made slopes, the tolerable SRs for loss of life are $10^{-4}$ per person per annum for the person at greatest risk and $10^{-6}$ per exposed person per annum as an average over the population at risk, respectively. For new slopes, the tolerable values are $10^{-5}$ per year and $10^{-6}$ per year, respectively. The difference in risk criteria for existing and new slopes is attributed to the differences in risk perceptions for existing and new slopes (Finlay and Fell, 1997). Similarly, AGS (2000) suggested tolerable individual risk levels in relation to slope failure. The tolerable SRs for the person most at risk are $10^{-4}$ per year and $10^{-5}$ per year for existing and new slopes, respectively. Based on a detailed review of the current international risk acceptance criteria in practice, GEO (1998) recommended an interim risk guideline for natural terrain landslides and boulder fall hazards in Hong Kong. The maximum tolerable individual risk levels for existing slopes and new slopes are recommended to be $10^{-4}$ and $10^{-5}$ per year, respectively. Leroi et al. (2005) summarized individual risk criteria in use in a number of engineering related disciplines, including landslides. There is a similarity among most of the aforementioned risk acceptance criteria (Fell and Hartford, 1997; AGS, 2000; GEO, 1998): the maximum tolerable individual risk level for existing slopes is $10^{-4}$ per year. This individual risk level is adopted to develop risk-based stabilization planning for deteriorating slopes in this study.

\section{Stabilization planning for deteriorating slopes}

Risk-based slope maintenance/stabilization planning can be developed based on the results described in the previous sections. The individual risk and societal risk of slope failures are expressed in terms of SR and TR, respectively. For illustrative purposes, the average vulnerability factor is obtained by dividing the number of fatalities by the number of slope failures. The number of soil cut slope failures and the total number of fatality between 1984 and 2002 in Hong Kong are 1123 and 18, respectively (Shiu and Cheung, 2003). The av- erage vulnerability factor in the same period is about 0.016 . This approach would grossly underestimate the actual vulnerability factor because the vast majority of the slope failures contained in the dataset have a low temporal probability of presence of population at risk. In practice, vulnerability factors commonly adopted in landslide quantitative risk assessment tend to be much higher than 0.01 . Therefore, in order to account for the effect of uncertainties in these vulnerability factors on the risk of slope failure, three values of vulnerability factor, $0.01,0.1$, and 1.0 are adopted in the subsequent analyses. As discussed earlier, SR values larger than $10^{-4}$ per year will be intolerable. Thus, if the SR for a slope failure is larger than $10^{-4}$ per year, stabilization actions should be taken. Since the societal risk acceptance criteria in terms of TR for slope failure have not been reported in the literature, for the purpose of this analysis, the maximum tolerable TR for slope failure is taken to be $10^{-3}$ fatalities per year. If the TR for a slope failure is larger than $10^{-3}$ fatalities per year, stabilization actions should also be activated. It should be noted that the maximum tolerable TR of $10^{-3}$ per year is adopted herein only for illustrative purpose. Strictly speaking, the maximum tolerable TR should account for the size of the considered zone. Taking the Hong Kong practices as an example, the existing landslide societal risk criteria based on F-N curve only apply to a consultation zone of $500 \mathrm{~m}$ slope boundary length.

As shown in Table 3, the expected number of fatalities for facility groups 1 to 5 are $3,1-2,0.25,0.03$, and 0.001 , respectively for slides $10 \mathrm{~m}$ in width and $50 \mathrm{~m}^{3}$ in volume individually. Therefore the societal risk of slope failure for a specified facility group directly affected by slope failure is a specific value. As mentioned earlier, if the actual slide size is different from the reference one assumed in the present study, then the expected number of fatalities should be scaled proportional to the ratio of the actual size to the reference size. Shiu and Cheung (2003) presented examples of calculated expected number of fatalities.

Based on the annual probability of failure in Fig. 10, the SRs within the first 16 years are plotted in Fig. 12 against the service time for three values of vulnerability factor. It can be seen from Fig. 12 that, as a slope deteriorates, the SR of slope failure increases with time and may reach an unacceptable level at a certain time. The SR of slope failure for the vulnerability factor of 0.1 increases from $1.37 \times 10^{-6}$ per year to $4.88 \times 10^{-4}$ per year as the service time increases from 1 year to 16 years. For a selected individual risk acceptance criterion, the maintenance time depends on the vulnerability factor in addition to factors that cause the slopes to deteriorate. The time for slope stabilization decreases with increasing vulnerability factor. For example, the time should be 11 year and larger than 16 years for vulnerability factors of 0.1 and 0.01 , respectively. In addition, if a SR of slope failure larger than $10^{-5}$ per year is considered unacceptable, then from Fig. 12 the times for stabilization are shortened to 4 and 11 years for vulnerability factors of 0.1 and 0.01 , 


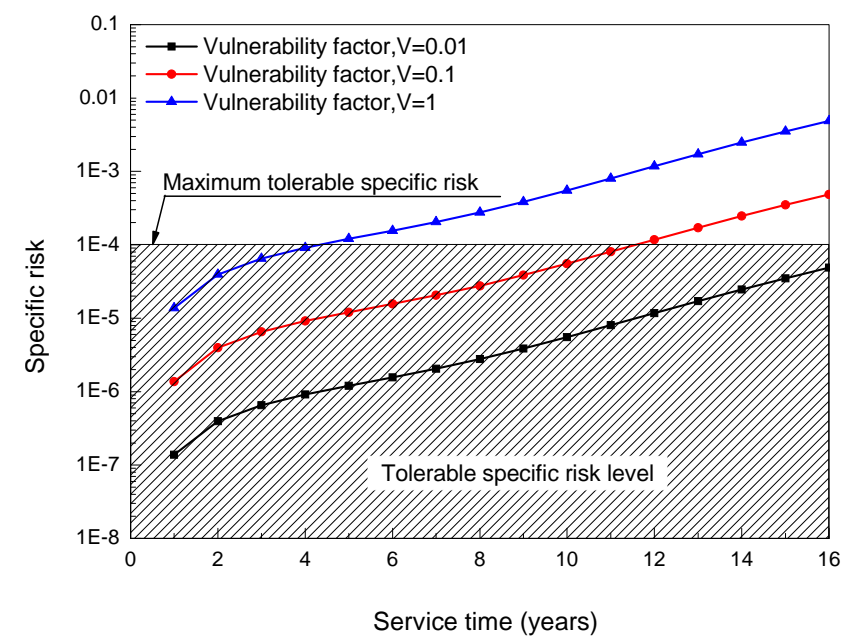

Fig. 12. Specific risk of soil cut slope failure by service time of slope.

respectively. This depends on the fact that the time for slope stabilization is very sensitive to risk criteria.

For societal risks of slope failure, based on the data in Fig. 10 and Table 3, Fig. 13 shows the variation of TR within the first 16 years with the service time for the vulnerability factor of 0.01. It can be seen from Fig. 13 that the risk of slope failure increases with the elements at risk. Let us take the slope at a service time of 15 years as an example. The TRs of slope failure for facility groups 1 to 5 directly affected by the reference slope range from $1.05 \times 10^{-4}$, (3.51$7.01) \times 10^{-5}$ to $3.51 \times 10^{-8}$ fatalities per year, respectively. The TR of slope failures may reach an intolerable level due to a change of elements at risk.

\section{Effect of maintenance/stabilization on reliability of slopes}

As indicated in Fig. 7, after a maintenance/stabilization plan has been implemented at a service time of 16 years, the Weibull parameters shown in Eq. (2) are not the same as those before 16 years. Based on Fig. 7 and Eq. (5), the probabilities of slope failure with and without maintenance or stabilization actions can be compared. Figure 14 presents the SRs on log scale against the extended service time after 16 years. Clearly, after the maintenance plan has been implemented, the deteriorating rate is well controlled and the SR only increases slightly with the service time. For example, when the service time increases from 17 to 50 years, the SR of slope failure for a global average vulnerability factor of 0.01 only increases from $1.42 \times 10^{-5}$ per year to $2.34 \times 10^{-5}$ per year. The corresponding SR values already lie within the tolerable individual risk level. In addition, the SR values for vulnerability factors of 0.1 and 1 are always above the threshold.

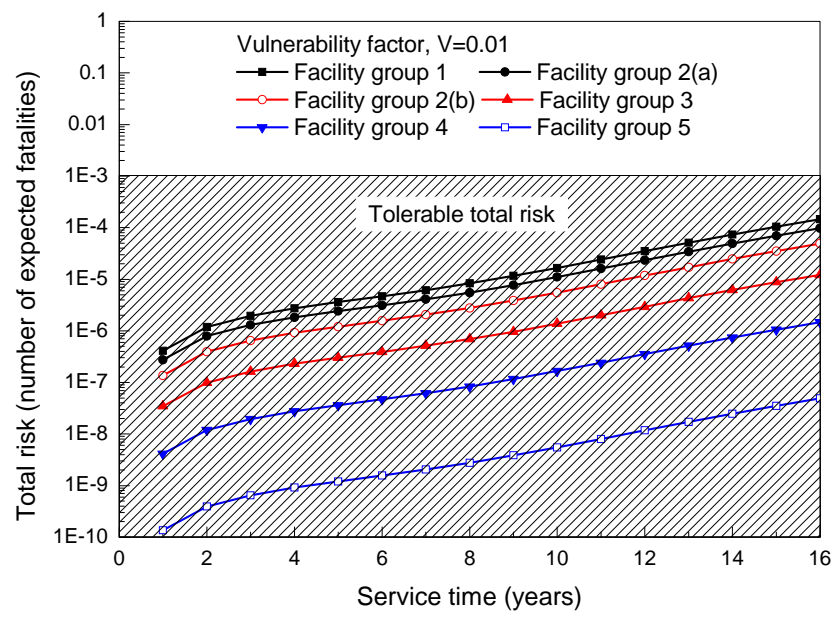

Fig. 13. Total risk of a reference landslide by service time of soil cut slope.

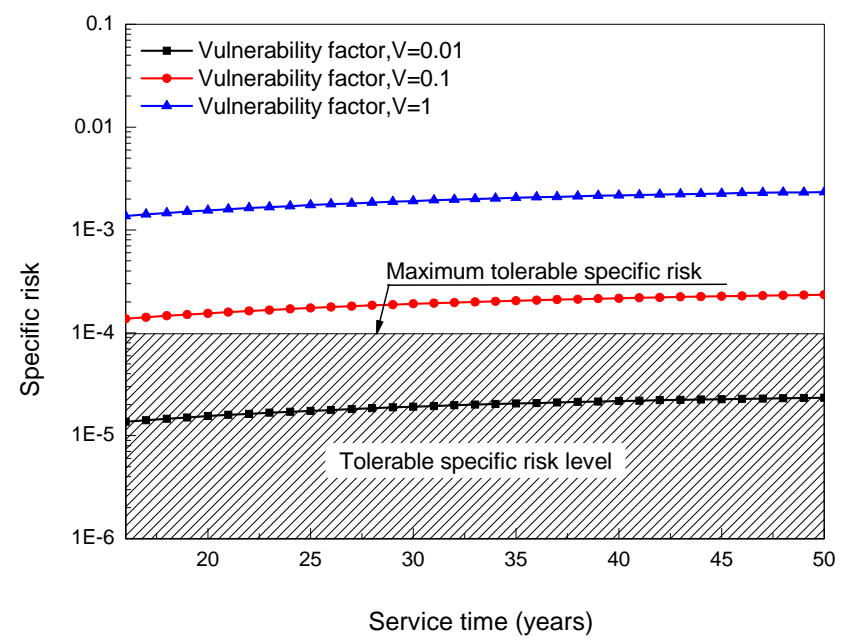

Fig. 14. Specific risk of soil cut slope failure after stabilization by service time of slope.

Figure 15 compares the SRs for 10-, 20- and 30-year old slopes within the next 30-year service period. As expected, the SRs for older slopes are higher than those for younger slopes given the same service period. For example, the 10-, 20 - and 30-year old cut slopes will have SRs of $1.56 \times 10^{-5}$, $1.99 \times 10^{-5}$ and $2.36 \times 10^{-5}$ per year over the next 10 -year service, respectively. In addition, the SRs for slopes of different ages become closer as the service time increases.

To further compare the effect of maintenance over time, Fig. 16 compares the probabilities of failure within the next service period for the slopes with and without maintenance for different rainfall intensity categories. The effect of maintenance on the probability of failure is most significant under the rainstorm category of $i_{24} \max =200-400 \mathrm{~mm} /$ day. Note that this range of rainfall probably corresponds to the one considered in future soil cut slope design. At a service time 


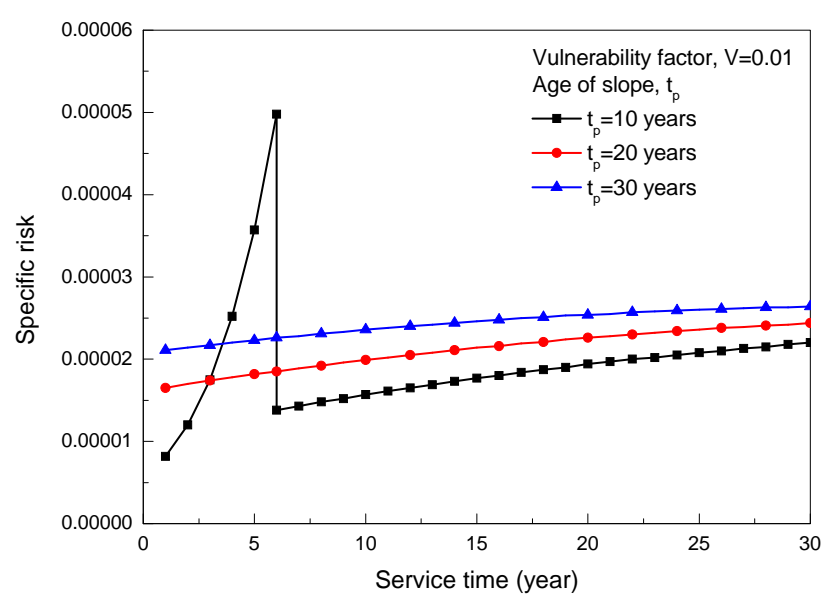

Fig. 15. Comparison between specific risks for soil cut slopes with different ages.

of 30 years, the probability of failure decreases substantially from $80 \%$ without maintenance or stabilization actions to $5.5 \%$ with proper maintenance. When considering the category of the rainfall intensity larger than $400 \mathrm{~mm} /$ day, a slope may fail in a single rainstorm event due to extreme water infiltration, rising ground water table, and surface or internal erosion; therefore, routine maintenance alone is not sufficient to guarantee the slope safety. Based on the results shown in Fig. 16, the effect of maintenance also depends on the rainfall intensity.

The probability of failure shown in Fig. 16 only represents the contribution of different categories of rainstorm to the conditional probability of failure. Similarly, applying Eq. (5), the cumulative probabilities of failure of slopes with and without maintenance/stabilization actions can be compared as shown in Fig. 17, by considering the different types of rainstorms. After a maintenance/stabilization plan has been implemented, the probability of failure decreases substantially. Generally, the reduction in the probability of failure increases with the service time. At a service time of 30 years, the cumulative probability of failure decreases from $41 \%$ (without slope maintenance/stabilization actions) to $4 \%$ (with proper slope maintenance/stabilization actions). This indicates the importance of a well-planned maintenance program.

\section{Conclusions}

This paper has proposed a methodology for risk-based maintenance/stabilization planning for deteriorating soil cut slopes, which may be used to improve the existing maintenance policies. The average time-dependent reliability for soil cut slopes can be effectively analyzed using the proposed methodology. The annual probability of failure of soil cut slopes would increase exponentially in the early stage of ser-

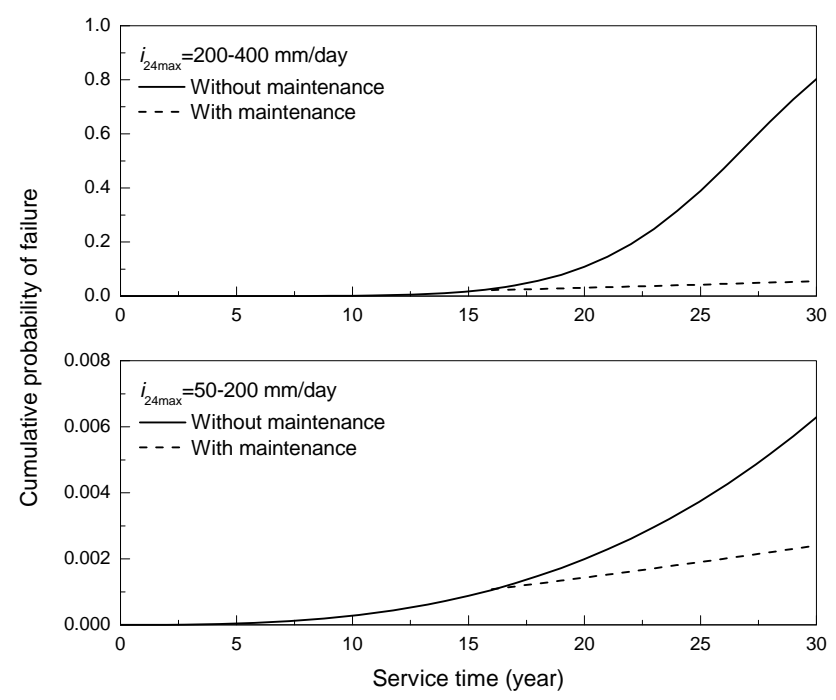

Fig. 16. Comparison between cumulative probabilities of failure of slopes using Eq. (4) with and without stabilization considering different categories of rainfall intensity.

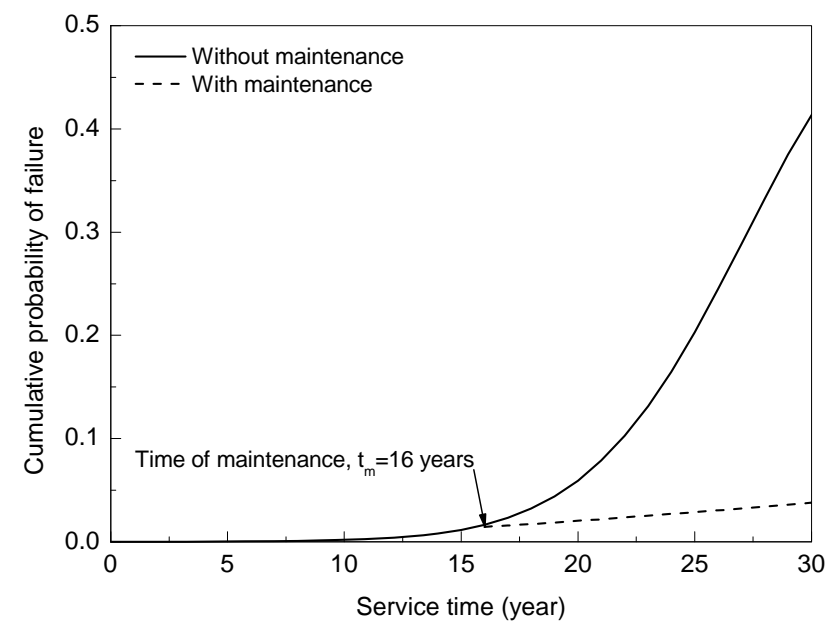

Fig. 17. Comparison between cumulative probabilities of failure for slopes using Eq. (5) with and without proper stabilization.

vice if no maintenance were implemented. The probability of slope failure increases as the rainfall intensity increases. The rate of slope deterioration increases significantly when the service time is longer than a decade. The annual probabilities of failure of slopes with different ages become similar as the service time increases. The global risks in terms of specific risk and total risk for soil cut slopes failures in the territory of Hong Kong are obtained. A maintenance/stabilization program for deteriorating slopes can be planned using the proposed risk-based methodology that provides a tool for maintenance planning to reduce the likelihood of slope failure and the corresponding consequence of failure. The time for slope stabilization is very sensitive to the tolerable risk criteria. 
Given selected risk criteria, the stabilization time depends on the rate of slope deterioration, the vulnerability of the affected population, and the consequence of slope failure. Stabilization works should be implemented to effectively control the rate of slope deterioration.

In the proposed methodology, the slope population is assumed to be homogeneous. Thus, the calculated reliability of soil cut slopes in this study only represents the average performance of slopes of similar characteristics. It may have little or even no meaning for individual slopes. Consequently, the calculated reliability and risk are global rather than site specific. However, the time-dependent reliability of a specific slope can be evaluated by using the average reliability of slopes as prior information in a Bayesian framework. The temporal and spatial distributions of heavy rainstorms relative to the locations of slopes of different vulnerabilities are not taken into account in this study. This is indeed an important area for further research. The scale of failures and the mobility of landslide debris are not considered. However, the proposed methodology can also be extended to account for the effect of the scale of failure and mobility of landslide debris. Only the maintenance time is illustrated, which affects the probability of slope failure directly, but affects the consequences of slope failure indirectly. However, the proposed methodology can be extended so that the consequences are addressed directly. This can be done by studying slope stabilization strategies that will be best applied to reduce the consequences. In addition, only the loss of life is considered in this paper. If the consequence of the landslide is only economical, then the presented methodology could be used for risk optimization in a cost-benefit analysis. The proposed method should also be extended to account for other consequences such as loss of property and socio-economic impacts.

Acknowledgements. This work is supported by National Natural Science Funds for Distinguished Young Scholars (Project No. 50725931), National Natural Science Foundation of China (Project No. 50839004), Program for New Century Excellent Talents in University, Ministry of Education of China (Project No. NCET-08-0415), and the Research Grants Council of the Hong Kong SAR (Project No. N_HKUST611/03).

Edited by: P. Reichenbach

Reviewed by: G. G. R. Iovine and another anonymous referee

\section{References}

$\mathrm{Au}, \mathrm{S}$. W. C.: Rain-induced slope instability in Hong Kong, Eng. Geol., 51(2), 1-36, 2001.

Australian Geomechanics Society: Landslide risk management concepts and guidelines, Australian Geomech, 35(1), 49-92, 2000.

Australian Geomechanics Society Landslide Taskforce: The Australian geoguides for slope management and maintenance, Australian Geomech, 42(1), 159-182, 2007a.
Australian Geomechanics Society Landslide Taskforce: Practice note guidelines for landslide risk management, Australian Geomech, 42(1), 63-114, 2007b.

Al-Khalil, M. Assaf, S., and Al-Anazi, F.: Risk-based maintenance planning of cross-country pipelines, J. Perform Constr. Facil., 19(2), 124-131, 2005.

Ang, A. H. S. and Tang, W. H.: Probability concepts in engineering: emphasis on applications to civil and environmental engineering, 2nd edition, John Wiley and Sons, New York, 2007.

Apeland, S. and Aven, T.: Risk based maintenance optimization: Foundational issues, Reliab. Eng. Syst. Safe, 67(3), 285-292, 2000.

Arunraj, N. S. and Maiti, J.: Risk-based maintenance-techniques and applications, J. Hazard. Mater., 142(3), 653-661, 2007.

Brand, E. W.: Predicting the performance of residual soil slopes. Proceedings of the 11th International Conference on Soil Mechanics and Foundation Engineering, San Francisco, Vol. 5, 2541-2578, 1985.

Chen, C. Y. Chen, T. C. Yu, F. C., and Lin, S. C.: Analysis of timevarying rainfall infiltration induced landslide, Environ. Geol., 48(4-5), 466-479, 2005.

Chen, H. and Lee, C. F.: Geohazards of slope mass movement and its prevention in Hong Kong, Eng. Geol., 76(1-2), 3-25, 2004.

Cheung, R. W. M.: Methodology for updating cut slope reliability based on observed performance, PhD Thesis, the Hong Kong University of Science and Technology, Hong Kong, 2004.

Cheung, R. W. M., Shiu, Y. K., and Pang, P. L. R.: Assessment of global landslide risk posed by man-made slopes in Hong Kong, Proceedings of the International Conference on LandslidesCauses, Impacts and Countermeasures, Davos, Switzerland, 497-505, 2001.

Cheung, R. W. M. and Tang, W. H.: Reliability of deteriorating slopes, J. Geotech. Geoenviron., 131(5), 589-597, 2005a.

Cheung, R. W. M. and Tang, W. H.: Realistic assessment of slope reliability for effective landslide hazard management, Geotechnique, 55(1), 85-94, 2005b.

Fell, R.: Landslide risk assessment and acceptable risk, Can. Geotech. J., 31(2), 261-272, 1994.

Fell, R. and Hartford, D.: Landslide risk management, In: Cruden DM, Fell R (eds) Landslide risk assessment, A.A. Balkema, Rotterdam, 51-109, 1997.

Finlay, P. J. and Fell, R.: Landslides: risk perception and acceptance, Can. Geotech. J., 34(2), 169-188, 1997.

Finlay, P. J., Fell, R., and Maguire, P. K.: The relationship between the probability of landslide occurrence and rainfall, Can. Geotech. J., 34(6), 811-824, 1997.

Finlay, P. J., Mostyn, G. R., and Fell, R.: Landslides: prediction of travel distance and guidelines for vulnerability of persons, in: Proceedings of the 8th Australia New Zealand Conference on Geomechanics, edited by: Vitharana, N. and Colman, R., 105113, 1999.

Fyfe, J. A., Shaw, R., Campbell, S. D. G., et al.: The quaternary geology of Hong Kong, Hong Kong: Geotechnical Engineering Office (GEO), 2000.

GEO.: Landslides and boulder falls from natural terrain: interim risk guidelines, GEO Report No. 75, Geotechnical Engineering Office (GEO), Hong Kong, 1998.

GEO.: Guide to slope maintenance (Geoguide 5), third edition, Geotechnical Engineering Office (GEO), Hong Kong, 2003. 
Glade, T.: Vulnerability assessment in landslide risk analysis, Die Erde, 134(2), 121-138, 2003.

Harr, M. E.: Reliability-based design in civil engineering, Dover Publications, Inc., Mineola, New York, 1997.

Lacasse, S.: Risk assessment for geotechnical solutions offshore, 23rd Int. Conf. on offshore mechanics and arctic engineering, ASME [CD ROM], 2004.

Lacerda, W. A. and Santos Jr., O. F.: Water table fluctuation - A cause of slide initiation in residual and colluvial soils in tropical regions, in: 8th Int. Symposium on landslides, edited by: Bromhead, E., Dixon, N., and Ibsen, M.-L., Thomas Telford, London, 877-880, 2000.

Lam, C. C. and Leung, Y. K.: Extreme rainfall statistics and design rainstorm profiles at selected locations in Hong Kong, Technical Note No. 86, Royal Observatory, Hong Kong, 1994.

Lee, W. F., Liao, H. J., Chen, R. H., Wei, C. Y., and Huang, Y. M.: The development and application of the slope management system, in: Geotechnical engineering in the information technology age, edited by: DeGroot, D. J., DeJong, J. T., Frost, D., and Baise, L. G., ASCE [CD ROM], 2006.

Leroi, E., Bonnard, C., Fell. R., and McInnes, R.: Risk assessment and management, in: Landslide risk management, edited by: Hungr, O., Fell, R., Couture, R., and Eberhardt, E., Taylor and Francis, London, 159-198, 2005.

Lo, D. O. K., Ho, K. K. S., and Wong, H. N.: Effectiveness of slope maintenance in reducing the likelihood of landslide, in: Proceedings of the Annual Seminar on slope engineering in Hong Kong, edited by: Li, K. S., Kay, J. N., Ho, K. K. S., A.A. Balkema, Rotterdam, 251-258, 1998.

Morgenstern, N. R.: Toward landslide risk assessment in practice, in: Landslide risk assessment, edited by: Cruden, D. M. and Fell, R., A.A. Balkema, Rotterdam, 15-23, 1997.

Muir, I., Ho, K. K. S., Sun, H. W., Hui, T. H. H., and Koo, Y. C.: Quantitative risk assessment as applied to natural terrain landslide hazard management in a mid-levels catchment, Hong Kong, in: Int. Conf. on geohazards-technical, economical and social risk evaluation, edited by: Nadim, F., Pottler, R., Einstein, H., Klapperich, H., and Kramer, S., Lillehammer, Norway [CD ROM], 2006.
Nelson, W.: Theory and applications of hazard plotting for censored failure data, Technometrics, 14(4), 945-966, 1972.

Premchitt, J.: Salient aspects of landslides in Hong Kong, in: 9th Asian Regional Conf. on soil mechanics and foundation engineering, Bangkok, Thailand, 497-502, 1991.

Premchitt, J., Brand, E. W., and Chen, P. Y. M.: Rain-induced landslides in Hong Kong, 1972-1992, Journal of the Hong Kong Institution of Engineers, 43-51, 1994.

Roberds, W. J.: Methodology for optimizing rock slope preventative maintenance programs, in: Proceedings of the Geotechnical Engineering Congress, ASCE, edited by: McLean, F. G., Campbell, D. A., and Harris, D. W., Reston, Va., 634-645, 1991.

Shiu, Y. K. and Cheung, R. W. M.: Case study on assessment of global landslide risk in Hong Kong, 9th Int. Conf. on applications of statistics and probability in civil engineering, Millpress, Rotterdam, 1393-1400, 2003.

Tang, W. H. and Cheung, R. W. M.: Performance-based modelling of slope reliability, in: 3rd Asian-Pacific Symposium on structural reliability and its applications, edited by: Cho, H. N., Yun, C. B., and Kim, S. H., 65-79, 2004.

Van Westen, C. J., Van Asch, T. W. J., and Soeters, R.: Landslide hazard and risk zonationwhy is it still so difficult?, Bull. Eng. Geol. Environ., 65(2), 167-184, 2006.

Varnes, D. J.: Landslide hazard zonation: a review of principles and practice, in: IAEG Monograph, Paris: UNESCO Press, 1984.

Wong, H. N. and Ho, K. K. S.: Systematic investigation of landslides caused by a serve rainstorm in Hong Kong, HKIE Transactions, 3(3), 17-27, 1997.

Wong, H. N., Ho, K. K. S., and Chan, Y. C.: Assessment of consequence of landslides, in: Landslide risk assessment, edited by: Cruden, D. M. and Fell, R., A.A. Balkema, Rotterdam, 111-149, 1997.

Wyllie, D. C., McCammon, N. R., and Brumund, W.: Planning slope stabilization programs by using decision analysis, Transp. Res. Record, 749, 34-39, 1980.

Yu, Y. F.: Correlations between rainfall, landslide frequency and slope information for registered man-made slopes, GEO Report No. 144, Geotechnical Engineering Office, Hong Kong, 2004. 